\title{
LA PROTECCIÓN AMBIENTAL COMO NORMA Y USO DEL TERRITORIO: EL EJEMPLO DEL SISTEMA NACIONAL DE UNIDADES DE CONSERVACIÓN DE LA NATURALEZA (SNUC) EN BRASIL
}

\section{ENVIRONMENTAL PROTECTION AS A NORM AND USE OF TERRITORY: THE EXAMPLE OF THE NATIONAL SYSTEM OF UNITS FOR NATURE CONSERVATION (SNUC) IN BRAZIL}

\author{
ANDRÉ VIEIRA FREITAS ${ }^{1}$ \\ Universidade de Brasília \\ andrevfr@gmail.com
}

Mirlei FACHINI VICENTE PeREIRA ${ }^{2}$

Universidade Federal de Uberlândia

mirlei@ufu.br

Fecha de recepción: 19 de mayo de 2020 / Fecha de aceptación: 1 de septiembre de 2020

RESUMEN: El Sistema Nacional de Unidades de Conservación de la Naturaleza (SNUC) constituye un conjunto de mecanismos normativos para la creación y la gestión de áreas protegidas en Brasil a partir de la actuación integrada de las distintas esferas político-administrativas del Estado. Su diseño legal prevé una serie de unidades de conservación que buscan garantizar la conservación y la preservación ambiental. Además de presentar la estructura del SNUC y su materialización en el territorio brasileño, este trabajo hace una reflexión sobre sus objetivos como usos del territorio y normas territoriales. El principal aporte pretendido es fomentar una comprensión integral de las áreas protegidas, como elementos inherentes a la dinámica del uso del territorio en Brasil.

\footnotetext{
${ }^{1}$ Estudiante de doctorado, Programa de Posgrado en Geografía, Universidade de Brasília (Brasil).

${ }^{2}$ Profesor investigador, Instituto de Geografía, Universidade Federal de Uberlândia (Brasil).
} 
RESUM: El Sistema Nacional d'Unitats de Conservació de la Naturalesa (SNUC) constitueix un conjunt de mecanismes normatius per a la creació i la gestió d'àrees protegides al Brasil a partir de l'actuació integrada de les diferents esferes políticadministratives de l'Estat. El seu disseny legal preveu una sèrie d'unitats de conservació que busquen garantir la conservació i la preservació ambiental. A més de presentar l'estructura de I'SNUC i la seva materialització en el territori brasiler, aquest treball fa una reflexió sobre els seus objectius com a usos del territori i normes territorials. La principal aportació pretesa és fomentar una comprensió integral de les àrees protegides, com a elements inherents a la dinàmica de l'ús del territori al Brasil.

ABSTRACT: The National System of Nature Conservation Units (SNUC) is a set of regulatory mechanisms for creation and management of protected areas in Brazil based on integrated action of the different political-administrative spheres of the State. Its legal design foresees a series of conservation units that seek to guarantee conservation and environmental preservation. In addition to presenting the structuration of SNUC and its materialization in the Brazilian territory, this paper reflects on its objectives as territorial uses and norms. The main contribution sought is to encourage a comprehensive understanding of protected areas as inherent elements of the dynamics of land use in Brazil.

Palabras claves: protección ambiental — unidades de conservación — territorio usado.

Paraules claus: protecció ambiental — unitats de conservación — territori usat.

Keywords: environmental protection - units for the conservation - using territory.

SUMARIO: I. Introducción. II. La categoría "territorio usado" como subsidio para el análisis ambiental. III. Normas territoriales. IV. El modelo brasileño de áreas protegidas. V. Consideraciones finales. VI Bibliografía.

\section{INTRODUCCIÓN}

En vista de la variedad de sus sistemas ambientales y sus especificidades ecológicas, la dimensión continental de su territorio y una historia marcada por la 
explotación intensiva de los recursos naturales, Brasil es un país cuya protección ambiental representa un desafío inmenso para la nación. Frente a este problema, el tema ambiental ha ingresado gradualmente a la agenda pública brasileña desde el siglo $\mathrm{XX}^{3}$, especialmente en sus últimas décadas, llevando a un marco regulatorio ambiental sólido que tiene la protección ambiental como uno de los objetivos principales. Eso se encuentra respaldado por la Constitución Federal de Brasil ${ }^{4}$ y por la ley que instituyó la Política Nacional del Medio Ambiente ${ }^{5}$.

Teniendo en cuenta la persistencia de este grande desafío para Brasil en el siglo XXI y considerando la necesidad de evolucionar hacia una perspectiva amplia con respecto a la protección ambiental, se creó para todo el país uno de los instrumentos más importantes de su política ambiental6: el Sistema Nacional de Unidades de Conservación de la Naturaleza (SNUC) ${ }^{7}$. Se trata de un arreglo sistémico normativo que define un conjunto de categorías de áreas protegidas, denominadas unidades de conservación, a partir de una actuación integrada en las esferas federal, estatal y municipal. Con el análisis de dicho sistema, este texto presenta una análisis y reflexión acerca del modelo brasileño de protección ambiental buscando investigar la siguiente cuestión: ¿cómo SNUC estimula la dinámica de usos del territorio en Brasil?

Ante la relevancia de considerar la dinámica territorial en el análisis del derecho ambiental, el objetivo es evaluar las acciones de protección, conservación y preservación ambiental como elementos de la dinámica de uso del territorio, examinando la estructura del modelo brasileño de áreas protegidas y reflexionando sobre ese modelo a partir de la argumentación teórica. En este sentido, se indica la

\footnotetext{
${ }^{3}$ Decreto 23793, de 23 de enero de 1934; Ley 4771, de 15 de septiembre de 1965; Ley 5191, de 3 de enero de 1967; Decreto 73030, de 30 de pcubre de 1973; Ley 6803, de 2 de julio de 1980; Ley 6902, de 27 de abril de 1981; Decreto 89.336, de 31 de enero de 1984; Decreto 98.914, de 31 de enero de 1990.

${ }^{4}$ La Constitución de la República Federativa de Brasil, de 1988, establece en su artículo 225 el derecho de todos a un medioambiente ecologicamente equilibrado y el deber del gobierno y la sociedad de protegerlo. Además, en este mismo artículo, establece que compete al poder público definir compartimentos territoriales protegidos $(\S 1, \mathrm{III})$.

${ }^{5}$ Ley 6938 , de 31 de agosto de 1981, artículos 2ำ, 6․ 9‥

${ }^{6}$ En su artículo 9이 la ley 6938, de 31 de agosto de 1981, considera como uno de sus instrumentos las áreas protegidas. Cuando se analisan sus objetivos (art. $2^{\circ}$ ), se nota que ese instrumento es muy estratégico para que esos propósitos sean cumplidos.

${ }^{7}$ EI SNUC fue instituído por la ley 9985, de 18 de julio de 2000, y regulado por el Decreto 4340, de 22 de agosto de 2002.
} 
necesidad de una mirada y comprensión amplia del SNUC, no solamente como un instrumento normativo estático de distintas áreas delimitadas, sino también como componente propio de la dinámica de uso del territorio.

Con respecto a los procedimientos metodológicos, la investigación se basa en revisión bibliográfica teórico-conceptual y temática, revisión bibliográfica documental y análisis de datos con representación cartográfica.

La revisión bibliográfica teórico-conceptual tiene como foco la categoría de análisis "territorio usado", concepto desarrollado por el geógrafo brasileño Milton Santos $^{8}$, y la revisión bibliográfica temática está centrada en la protección ambiental.

Sobre el marco empírico, el texto desarrolla una revisión bibliográfica documental, con el análisis de la legislación ambiental sobre áreas protegidas en Brasil, principalmente el SNUC, pero incluye también otras normas anteriores.

Además, son presentados datos de 2020 sobre sobre la materialización de las unidades de conservación en el territorio brasileño, extraídos del Registro Nacional de Unidades de Conservación de la Naturaleza de Brasil (CNUC) ${ }^{9}$.

La representación cartográfica utilizó datos ráster y vectoriales. En cuanto a los datos ráster, se utilizaron imágenes georreferenciadas del satélite Landsat 8 de 2015 que Google Maps puso a disposición. La información vectorial proviene de agencias federales brasileñas. Los datos sobre las unidades de conservación se extrajeron de la base de datos del Ministerio del Medio Ambiente y sobre deforestación del Instituto Nacional de Investigaciones Espaciales (INPE). Los datos cartográficos del territorio brasileño, incluido el mar territorial y la Zona Económica Exclusiva, la delimitación de la Amazonia Legal brasileña, así como las divisiones político-administrativas de los otros países sudamericanos, fueron extraídos de la base de datos del Instituto Brasileño de Geografía y Estadística (IBGE). El software utilizado para producir los mapas fue QGIS 3.8.3 y el acceso a los datos ráster fue a través de la extensión QuickMapServices.

\footnotetext{
${ }^{8}$ Milton Santos. "O retorno do território". Observatorio Social de América Latina, núm. 16, 2005.

${ }^{9}$ Ministério do Meio Ambiente (Brasil). Cadastro Nacional de Unidades de Conservação. El banco de datos es mantenido y gerenciado por el Ministerio del Medio Ambiente (MMA), pero depende de las informaciones prestadas por los órganos administradores de cada unidad de conservación. Los datos son constantemente actualizados y pueden tener algunos desajustes.
} 
Además de la introducción y de algunas consideraciones finales, el desarrollo del texto se estructura en tres secciones: la primera apunta un debate acerca de la categoría territorio usado; la segunda aborda las normas territoriales; la tercera y última sección discurre sobre el modelo brasileño de protección ambiental, a partir de la reflexión sobre áreas protegidas, conservación y preservación ambiental.

\section{LA CATEGORÍA “TERRITORIO USADO” COMO SUBSIDIO PARA EL ANÁLISIS AMBIENTAL}

Como instrumento legal y definidor de las categorías de áreas protegidas para la política ambiental brasileña, el SNUC se materializa en el territorio y tiene implicaciones en la dinámica de sus usos a partir de la regulación de una serie de porciones territoriales definidas como unidades de conservación, donde se inducen o se reprimen acciones para lograr la protección ambiental. Ese raciocinio permite analizar las áreas protegidas como compartimentaciones territoriales a partir de las normas, de acuerdo con el derecho ambiental, y de sus usos, con base en el marco teórico de la geografía.

En el ámbito jurídico, el territorio se relaciona con la idea de jurisdicción y el locus de la soberanía estatal ${ }^{10}$, como en la definición clásica de territorio como "el dominio espacial vigencia de un orden jurídico estatal"11. Al respecto del derecho ambiental, aunque se reconozca el principio de la soberanía estatal, también se presenta la tutela internacional del medioambiente, considerando las obligaciones internacionales asumidas en ese ámbito. Sobre el abordaje del territorio en esa rama contemporánea del derecho, se nota un enfoque relacionado a la gestión de los recursos naturales y la obligación del Estado de proteger el patrimonio ambiental, además de un abordaje en cuanto a las diferentes competencias en su estructura político-administrativa ${ }^{12}$. Ese es el espíritu adoptado por la Constitución Federal brasileña acerca de la noción te territorio. También es relevante en el derecho ambiental brasileño el reconocimiento de

\footnotetext{
10 Manoel Gonçalves Ferreira Filho. Curso de direito constitucional. São Paulo: Saraiva, 2015, p. 46 [traducción propia].

11 Márcio Antônio Cataia. "Território político: fundamento e fundação do Estado". Sociedade \& Natureza, núm. 1, 2011, p. 117.

12 Márcia Dieguez Leuzinger (et al). Direito Ambiental. Rio de Janeiro: Elsevier, 2008.
} 
áreas protegidas como compartimentos territoriales estratégicos, lo que justifica su implementación ${ }^{13}$.

Además de la consideración de elementos como jurisdicción, atribución de competencias, el patrimonio ambiental y la gestión de los recursos naturales, que son relevantes en la concepción de territorio para el derecho ambiental, las áreas protegidas podrían ser examinadas a partir del concepto de "territorio usado"14, que tiene gran potencial de contribución al análisis ambiental.

La categoría territorio usado aparece en la obra de Milton Santos ${ }^{15}$ para dar énfasis a la relación entre espacio geográfico y territorio, con el objetivo de resaltar la dinámica espacial y su materialización, lo que incluye también la dimensión natural. Si el espacio geográfico ${ }^{16}$ debe ser entendido como una instancia inherente a toda acción social, cuya expresión más directa conlleva un conjunto inseparable, solidario y contradictorio de sistemas de objetos y sistemas de acciones ${ }^{17}$, el territorio es justamente su dimensión materializada ${ }^{18}$, un campo de fuerzas ${ }^{19}$ que, por su vez, se relaciona con el ambiente (sinónimo de medio geográfico) ${ }^{20}$. El territorio usado es justamente la realización constante de la dinámica espacial: los sistemas de objetos y

\footnotetext{
13 Pereira Polyana Faria, Scardua Fernando Paiva. "Espaços territoriais especialmente protegidos: conceito e implicações jurídicas". Ambiente \& Sociedade, núm, 1, 2008.

${ }^{14}$ Santos, "O retorno do território..." cit.

${ }^{15}$ Ibíd.

${ }^{16}$ La categoría espacio geográfico es central en la teoría de Milton Santos. Reflexionando sobre la relación entre la sociedad y el medio, el autor comprende que el espacio geográfico es "la naturaleza modificada por el hombre a través de su trabajo" (p. 150). En su dimensión historica, "se define por um conjunto de relaciones sociales del pasado y del presente" y por una estructura representada por relaciones sociales que se manifestan a través de procesos y funciones (p. 153). Santos, M. Por uma geografia nova: da crítica da geografia a uma geografia crítica. Hucitec. São Paulo, 1986.
}

17 Milton Santos. A natureza do espaço: técnica e tempo, razão e emoção. Editora da Universidade de São Paulo. São Paulo, 2008.

${ }^{18}$ Ana Clara Torres Ribeiro. "Território usado e humanismo concreto: o mercado socialmente necessário". En: Ana Clara Torres Ribeiro. (et al). Formas em crise: utopias necessárias. Arquimedes Edições. Rio de Janeiro, 2005.

${ }^{19}$ Milton Santos. "O Território e o Saber Local: algumas categorias de análise". Cadernos IPPUR, núm. 2, 1999.

20 Milton Santos. "A questão do meio ambiente: desafios para a construção de uma perspectiva transdisciplinar". GeoTextos, núm. 1, 2006. 
de acciones ${ }^{21}$ efectivados, su base material (re)ordenándose, el medio (ambiente) reconstruyéndose a partir de la relación de la sociedad con la naturaleza. Como destaca Santos, "el territorio usado es el conjunto de objetos y acciones, sinónimo de espacio humano, espacio habitado."22.

Se trata, como destaca Cataia, de comprender la materialidad y su uso en la comprensión del territorio. Para el autor, "la definición de territorio debe considerar la interdependencia y la inseparabilidad entre las materialidades (que contempla los objetos naturales y artificiales) y su uso referido a las acciones humanas, o sea, al trabajo y a la política."23.

De ese modo, el concepto de territorio usado invita a considerar la dinámica espacial en proceso, su materialización. "Es el territorio propiamente dicho más las sucesivas obras humanas y los hombres en la actualidad. Es el territorio hecho y el territorio haciéndose"24, es decir, visto como proceso.

Esa realización de la dinámica espacial ocurre por medio de las acciones sociales que dan vida a los objetos, o sea, el uso del territorio, que puede ser entendido de diversas maneras, de acuerdo con las diferentes acciones humanas articuladas en sistema. Para Santos y Silveira:

el uso del territorio puede ser definido por la implementación de infraestructuras, para las cuales estamos utilizando la denominación de sistemas de ingeniería, sino también por el dinamismo de la economía y de la sociedad. Son los movimientos de la población, la distribución de la agricultura, de la industria y de los servicios, el andamiaje normativo, incluidas la legislación civil, fiscal y financiera, que, juntamente con el alcance y la extensión de la ciudadanía, configura las funciones del nuevo espacio geográfico"25.

A partir de esta visión de tales circunstancias y acciones que definen el uso del territorio, se podría reflexionar sobre la identificación empírica de usos del territorio, en

\footnotetext{
${ }^{21}$ Los objetos geográficos, que incluyen los objetos naturales (como ríos y cerros) y artificiales (como puentes y edificios), tienen funciones distintas para la sociedad y se distribuyen en sistemas en el espacio. Las acciones (tambien como sistemas) interactuam con los objetos, son influenciadas por ellos, crean nuevos objetos y transforman sus formas, funciones y estructuras.

${ }^{22}$ Santos, "O retorno do território..." cit., p. 255 [traducción propia].

${ }^{23}$ Cataia, "Território político..." cit., p. 123 [traducción propia].

${ }^{24}$ María Laura Silveira. "Globalización y territorio usado: imperativos y solidaridades". Cuadernos del CENDES, núm. 69, 2008, p. 3.

${ }^{25}$ Milton Santos; María Laura Silveira. O Brasil: território e sociedade no início do século XXI. Record. Rio de Janeiro, 2008, p. 21 [traducción propia].
} 
plural. Con la salvedad de que dichos usos no pueden ser vistos de manera aislada sino como un sistema, pues son parte del movimiento general del territorio usado, se puede defender que los usos del territorio denotan modos por los cuales se expresa la transformación de la naturaleza por medio del trabajo humano ${ }^{26}$, involucran la materialidad y la vida social, en un conjunto de sistemas de objetos y sistemas de acciones $^{27}$.

Además, teniendo en cuenta que el uso del territorio es social y por ello complejo y plural, es necesario ampliar el campo de visión hacia el conjunto de acciones en el territorio, captando la pluralidad de este uso, lo que invita a reflexionar acerca de los múltiples usos del territorio que, en conjunto, realizan la dinámica espacial. No se trata, cabe resaltar nuevamente, de tomar las acciones como autónomas, ya que no se realizan de modo aislado, sino de comprenderlas como distintos usos del territorio articulados en sistema. Como identifica Cataia, "el territorio, un híbrido de objetos naturales $\mathrm{y}$ artificiales $\mathrm{y}$ acciones sociales, pide un procesamiento analítico $\mathrm{y}$ sistemático: las materialidades y sus usos; usos que son acciones humanas trabajadas y politizadas"28.

Con tal espíritu es posible reflexionar sobre diferentes acciones o conjuntos de acciones complejas que denotan una determinada relación con los objetos geográficos naturales y artificiales y que, por lo tanto, pueden ser comprendidas como usos del territorio, inclusive los sistemas de protección ambiental.

Estas consideraciones contribuyen inicialmente a una reflexión sobre las áreas protegidas y sus objetivos de protección, conservación y preservación ambiental, objeto principal de este texto que, en última instancia, también constituyen un uso territorial. Pero antes de defender tal hipótesis, cabe destacar otro elemento en el análisis sobre la categoría territorio usado, la reflexión sobre normas territoriales.

\footnotetext{
${ }^{26}$ Santos. "Por uma geografia nova...".

${ }^{27}$ Santos, "A natureza do espaço..." cit.

${ }^{28}$ Cataia, "Território político..." cit., p. 121.
} 


\section{NORMAS TERRITORIALES}

Los distintos usos del territorio, efectuados por las acciones que animan y confieren dinamismo a la materialidad, incluyendo objetos geográficos naturales y artificiales, son afectados por las normas territoriales. Las normas constituyen una "estrategia de regulación del territorio"29, porque influencian la dinámica de sus usos.

Partiendo, en la perspectiva de Santos $^{30}$, del entendimiento de espacio geográfico como un conjunto inseparable de sistemas de objetos y sistemas de acciones, Antas $\mathrm{Jr}^{31}$ considera que la norma, tal como la técnica, se presenta en la relación entre estos sistemas. Según el autor, "la inseparabilidad entre acciones y objetos puede, en parte, ser comprendida por medio de un análisis vertical del papel de la técnica y de la norma."; además, "las acciones solo se realizan por medio de la técnica y de la norma"32.

Retomando la idea de $\operatorname{Santos}^{33}$ que la técnica es mediadora de la relación sociedad-naturaleza, Antas Jr. apunta que ahí se constituye la norma.

La técnica, y no simplemente la fuerza de trabajo, es el modo por el cual los hombres se relacionan con la naturaleza (natural y recriada), atribuyendo a la materialidad intencionalidades condicionadoras de las acciones. En otras palabras, a partir de una dada configuración de los objetos técnicos, intencionalmente establecida, se deriva la repetición de determinado conjunto de acciones (aun cuando no imposibilite acciones inusitadas). Así emerge la norma: como la resultante de un condicionamiento que produce la rutina de dicho evento. ${ }^{34}$

De este modo, se pueden identificar distintas densidades normativas, como reconoce el autor:

Hay, por lo tanto, en la interacción entre objetos y acciones, la presencia de densidades normativas variadas, conforme la cantidad y la calidad con que estos dos elementos se

\footnotetext{
29 Mirlei Fachini Vicente Pereira. "O antagonismo das normas territoriais no sudoeste da Amazônia: território usado e conflito de interesses em Rondônia e Acre". Geografia, Num. Especial, 2011, p. 109.

${ }^{30}$ Santos, "A natureza do espaço..." cit.

${ }^{31}$ Ricardo Mendes Antas Jr. Território e regulação: espaço geográfico como fonte material e não-formal do direito. Humanitas/FAPESP. São Paulo, 2005.

32 lbíd, p. 59 [traducción propia].

${ }^{33}$ Santos, "A natureza do espaço..." cit.

${ }^{34}$ Antas Jr, "Território e regulação..." cit., p. 58-59 [traducción propia].
} 
distribuyen por la superficie terrestre, y gran parte de esas normas, jurídicas, busca regular tal relación. ${ }^{35}$

De acuerdo con Silveira, las propias normas, en sus distintas densidades, tienen concreción gracias a su función organizacional. En las palabras de la autora: "De la misma manera que los objetos son, hoy, concretos por la convergencia entre su planificación y su construcción, las normas manifestarían su concreción gracias a la coincidencia entre su concepción y su función organizacional."36.

Sin embargo, la idea de Silveira está relacionada con la "concreción territorial". Considerando la creciente hibridez de los objetos, acciones y normas y su distribución de modo diverso en el territorio, la autora reconoce distintas densidades informacionales y normativas. A ese cuadro diverso, Silveira denomina "concreción territorial"37.

Las normas tienen naturalezas distintas. Según Antas Jr., de la interacción entre objetos y acciones derivan algunos tipos de normas: a) "Normas derivadas de objetos técnicos, o de un conjunto de objetos técnicos, rigiendo las acciones involuntariamente" (como el acto de habitar una residencia); b) "Normas que parten de las acciones sobre el uso de los objetos en función de una necesidad socialmente aceptada" (como los estándares de funcionalidad de las construcciones); c) "Normas que limitan las posibilidades de uso de un objeto o sistema técnico en diversas direcciones o vectores." (En general la norma jurídica) ${ }^{38}$.

Se trata, por lo tanto, de una comprensión amplia de normas y su caracterización como normas territoriales, y no exclusivamente como normas jurídicas. Acerca de las normas jurídicas, sus densidades son significativas en el territorio, entre otros factores, porque son formalmente reconocidas y pueden llevar a sanciones, lo que refuerza su papel regulador. Segundo Antas Jr. "la sanción establece un límite a la acción, y eso se aplica tanto al uso de un objeto técnico cuanto al uso del territorio"39. Valiéndose de eso,

\footnotetext{
35 Ibíd, p. 52 [traducción propia].

${ }^{36}$ María Laura Silveira. "Concretude territorial, regulação e densidade normativa". Experimental. Núm. 2, 1997, p. 40, [traducción propia].

37 lbíd.

${ }^{38}$ Antas Jr, "Território e regulação..." cit., p. 64 [traducción propia].

39 lbíd., p. 65 [traducción propia].
} 
según el autor: "Las normas jurídicas regulan la producción de los sistemas y objetos técnicos y las acciones que inciden sobre esos objetos, según finalidades que varían conforme el contexto socioeconómico de cada período histórico." ${ }^{\circ}$.

Sin embargo, las normas no son solamente formales, sino que se relacionan a otros campos de la sociedad ${ }^{41}$. Pueden ser tanto formales, jurídicas o informales, a partir de la vivencia, de las tradiciones, del cotidiano. En ese sentido, hay que comprender las normas en un sentido amplio. Además, las diferentes normas cambian con el proceso histórico.

Las normas no se restringen a leyes. Pueden ser reglas de una comunidad o hasta de organismos internacionales. Así, se puede decir que las normas y la materialidad del territorio incentivan determinados usos y cercenan otros. Sin embargo, tanto la materialidad de los usos del territorio como sus reglas se modifican a lo largo del tiempo. ${ }^{42}$

Así se nota que las normas, incluyendo las jurídicas, son mutables. A la vez que inducen o reprimen determinados usos del territorio, las normas son también afectadas por los propios usos, que, de este modo, también se afirman como normas territoriales.

También remetiéndose al entendimiento sobre el espacio como un conjunto inseparable de sistemas de objetos y sistemas de acciones ${ }^{43}$, Silveira presenta las acciones como definidoras de normas. Según la autora: "Cristalizadas en estructuras de diversas naturalezas, algunas de estas acciones se tornan principios para otras, mejoran y completan el modo de usar objetos y, nos permiten, así, reconocer normas." ${ }^{44}$ Como ya se ha visto, las acciones indican usos del territorio, lo que corrobora la afirmación de que estos usos también se presentan como normas territoriales.

En este sentido, Silveira ve el propio territorio usado como una norma ${ }^{45}$. La propia materialidad (el territorio en sí: los objetos) ya se constituye como norma, pero

\footnotetext{
40 lbíd., p. 65 [traducción propia].

41 lbíd.

42 Maiara da Silva Gomes (et al). "O potencial político da categoria 'território usado'". En: Marília Steinberger. (Coord.). Território, Estado e políticas públicas espaciais. Ler Editora. Brasilia: 2013, p. 80 [traducción propia].

${ }^{43}$ Santos, "A natureza do espaço..." cit.

${ }^{44}$ Silveira, "Concretude territorial..." cit., p. 37.

45 Silveira, "Globalización y territorio usado..." cit.
} 
cuando es animada por las acciones (el territorio usado: objetos + acciones) esto es aún más correcto. Para la autora,

el territorio usado es una norma, pues es un principio o un molde para la acción presente, la cual, dotada de poder desigual para transformar lo que existe o para concretar lo posible, ejercita nuevos usos, esto es, crea más objetos y normas. ${ }^{46}$

Esas nuevas normas creadas por los nuevos usos se relacionan con las normas ya establecidas, que pueden ser tanto recreadas/reinventadas como transgredidas, lo que depende de la correlación de fuerzas entre los agentes, que luchan por la ejecución de determinados usos, creando o transgrediendo normas. En ese sentido, las normas invitan a pensar sobre las relaciones de poder y los conflictos (así como las complementariedades) sobre el uso del territorio.

Las normas están entonces profundamente ligadas a relaciones de tensión/armonía entre objetos y acciones ${ }^{47}$, así como a las relaciones de poder entre los agentes que animan la materialidad y, así, usan el territorio. En este sentido, algunas normas, como las jurídicas, remeten al papel del Estado, de modo a que se repriman o induzcan algunos usos en detrimento de otros. Una de las maneras por la cual ocurre esa actuación del Estado es por medio de las normas legales y otra ocurre por medio de las políticas públicas y sus instrumentos ${ }^{48}$ que, como orientaciones sobre los usos del territorio, también podrían ser comprendidas como normas, dado que orientan usos y ordenan el territorio.

Se percibe, entonces, que la reflexión sobre normas territoriales, además de ser relevante para la categoría territorio usado, es importante para la investigación sobre las acciones del Estado, en especial las políticas públicas para la dimensión ambiental, cuando se contemplan las áreas protegidas. Considerando este auxilio teórico tomado del análisis sobre usos del territorio y normas territoriales, la siguiente sección evalúa y

\footnotetext{
46 Ibíd., p. 4.

${ }^{47}$ Antas Jr, "Território e regulação..." cit., p. 61.

48 Cuando las políticas públicas son reconocidas como una función del Estado, se nota que están esencialmente ligadas a las normas jurídicas, pues son implementadas a partir de actos del Poder Público (tanto por el Poder Legislativo como por el Poder Executivo): leyes, decretos, actos de la Administración Pública etc.
} 
trae una reflexión basada en el modelo brasileño de áreas protegidas, discutiendo también las nociones de protección, conservación y preservación ambiental.

\section{El modelo brasileño de áreas protegidas}

En el año $2000^{49}$ fue aprobado un importante instrumento de la política ambiental brasileña específico para las áreas protegidas: el Sistema Nacional de Unidades de Conservación da Naturaleza (SNUC). Ese arreglo sistémico de áreas protegidas se basa en la idea de protección ambiental y en sus desdoblamientos, la conservación y la preservación ambiental, a partir de una tipología de áreas protegidas, denominadas como unidades de conservación ${ }^{50}$.

Analizando el modelo brasileño, Medeiros ${ }^{51}$ destaca que las áreas protegidas involucran tanto a las unidades de conservación, que son reguladas por el SNUC, como a otras tipologías, como las Áreas de Preservación Permanente (APP) ${ }^{52}$, Reserva Legal $(R L)^{53}$ o incluso tierras indígenas. Según el autor: "Las áreas protegidas son espacios

\footnotetext{
49 La aprobación de la Ley 9985 ocurrió en 18 de julio de 2000, pero su discusión en el Congreso Nacional de Brasil se inició en 1992, como proyecto de Ley del Ejecutivo Federal, después de intensa discusión en este Poder. Además, la idea de un sistema como ese ya era discutida en las instituciones del Estado desde la década 1970. Esa historia del SNUC concide con algunos eventos importantes relativos a un crescimiento de importáncia de la temática ambiental en la agenda pública en Brasil. Justo en los año 1970 fue creada la Secretaria Especial del Medio Ambiente de Brasil, una sinalización interna delante de un movivimiento global de preocupación ambiental (en 1972 se realizó la Conferéncia de las Naciones Unidas sobre el Medio Ambiente Humano). En 1992 fue creado el Ministério del Medio Ambiente de Brasil, mismo año de la realización de la Conferéncia de las Naciones unidas sobre el Medio Ambiente y Desarrollo, que tuvo lugar en Río de Janeiro.

${ }^{50} \mathrm{La}$ terminología corresponde a una serie de diferentes tipos de áreas protegidas contempladas en el ámbito del SNUC. Estas porciones abarcan tanto áreas protegidas instituidas por normas anteriores a la Ley 9985/2000 como a nuevas áreas propuestas por el SNUC (Cuadro 1).

${ }^{51}$ Rodrigo Medeiros. Evolução das tipologias e categorias de áreas protegidas no Brasil. Ambiente \& Sociedade, núm. 1, 2006.

52 Áreas naturales sensibles a las acciones antrópicas (como nacientes, plantas ciliares y cimas de cerros) destinadas a la preservación de los recursos hídricos, del paisaje, de la estabilidad geológica y de la biodiversidad, la protección del suelo y la seguridad del bienestar de las poblaciones (Ley 12651, de 31 de agosto de 2012, art. 3은 II; $4^{\circ}$ ).

${ }^{53}$ Área localizada dentro de propiedades rurales con la función de asegurar uso económico sostenible de los recursos naturales, auxiliar la conservación y la rehabilitación de los procesos ecológicos y promover la conservación de la biodiversidad, así como el abrigo y la protección de la fauna silvestre y de la flora nativa. Su delimitación varía de acuerdo con el bioma y otros criterios definidos en ley (Ley 12651/2012, Art. 3이 III; 12-14).
} 
territorialmente demarcados cuya función principal es la conservación y/o la preservación de recursos, naturales y/o culturales, asociados a ellas" ${ }^{\prime 24}$.

Eligiendo una serie de áreas protegidas como unidades de conservación (cuadro 1), el SNUC constituye un conjunto sistemático de categorías de manejo de los recursos naturales, en el ámbito federal, estatal/distrital y municipal ${ }^{55}$. Las unidades de conservación son agrupadas en las categorías "Unidades de Protección Integral" y "Unidades de Uso Sostenible", además de las Reservas de la Biosfera ${ }^{56}$, comprehendida por Medeiros ${ }^{57}$ como parte de una categoría especial.

Uno de los grandes méritos de SNUC fue reunir, a partir de un marco legal único, un conjunto de áreas protegidas que estaban desarticuladas en la legislación brasileña desde la década de $1930^{58}$, además de adecuar la tipología de áreas protegidas del país a referencias de la Unión Internacional para la Conservación de la Naturaleza $(\mathrm{UICN})^{59}$ y proponer nuevas categorías de unidades de conservación ${ }^{60}$.

\footnotetext{
${ }^{54}$ Medeiros, "Evoulção das tipologias..." cit., p. 41 [traducción propia].

55 Para complementar la Ley federal, los otros entes federados de Brasil (estados, Distrito Federal y Municipios) pueden instituir sus respectivos sistemas de unidades de conservación, aprobados por norma legal propia, pudiendo inclusive proponer otras tipologías específicas para su ámbito propio. El conjunto de estas unidades de conservación federales, estatales, distritales y municipales constituyen el sistema nacional, que debe ser administrado de manera articulada. (Ley 9.985/2000, art. $3^{\circ}, 6^{\circ}$ ).

${ }^{56}$ Las reservas de la biosfera fueron incorporados al texto del SNUC (Ley 9985, de 18 de julio de 2000, art. 41), ratificando el Programa Intergubernamental "El Hombre y la Biosfera" [Man and the Biosphere], establecido por la UNESCO. Constituyen grandes extensiones de tierras, incluyendo diferentes categorías de unidades de conservación y otras áreas.

${ }^{57}$ Medeiros, "Evolução das tipologias..." cit.

58 Como: el Código Forestal de 1934 (Decreto 23793, de 23 de enero de 1934), que estableció las Florestas Nacionales y los Parques Nacionales (regulados por el Decreto 84017, de 21 de septiembre de 1979); el Código Forestal de 1965 (Ley 4771, de 15 de septiembre de 1965) y la Ley de Protección a la Fauna (Ley 5191, de 3 de enero de 1967), que establecieron las Reservas Biológicas; la Ley 6902, de 27 de abril de 1981, que estableció las Estaciones Ecológicas y las Áreas de Protección Ambiental; el Decreto 89336, de 31 de enero de 1984, que estableció las Áreas de Relevante Interés Ecológico; además del Decreto 98914, de 31 de enero de 1990, que estableció las Reservas Particulares del Patrimonio Natural.

59 Haroldo Camargo Barbosa. "Aspectos que estruturam o sistema nacional de unidades de conservação da natureza". Revista Jurídica da UniFil, núm. 5, 2018.

${ }^{60}$ Como las categorías "Monumento Natural" (art. 12), "Refúgio de Vida Silvestre" (art. 13), "Reserva de Fauna" (art. 19) y "Reserva de Desarrollo Sostenible" (art. 20) (Ley 9985, de 18 de julio de 2000).
} 
Cuadro 1: Categorías de unidades de conservación de la naturaleza en el SNUC

\begin{tabular}{|c|c|c|}
\hline GRUPO & CATEGORIA & OBJETIVO \\
\hline \multirow{5}{*}{$\begin{array}{l}\text { Unidades } \\
\text { de } \\
\text { Protección } \\
\text { Integral }\end{array}$} & Estación Ecológica & $\begin{array}{l}\text { Preservar la naturaleza y viabilizar investigaciones } \\
\text { científicas. }\end{array}$ \\
\hline & Reserva Biológica & Preservar la biota y otros atributos naturales. \\
\hline & $\begin{array}{l}\text { Parque Nacional, } \\
\text { Estatal, Natural } \\
\text { Municipal }\end{array}$ & $\begin{array}{l}\text { Preservar ecosistemas naturales de grande relevancia } \\
\text { ecológica y belleza escénica. }\end{array}$ \\
\hline & Monumento Natural & $\begin{array}{l}\text { Preservar sitios naturales raros, singulares o de belleza } \\
\text { escénica. }\end{array}$ \\
\hline & $\begin{array}{l}\text { Refugio de Vida } \\
\text { Silvestre }\end{array}$ & $\begin{array}{l}\text { Proteger ambientes naturales y la existencia o } \\
\text { reproducción de especies o comunidades de la flora } \\
\text { local y de la fauna residente o migratoria. }\end{array}$ \\
\hline \multirow{7}{*}{$\begin{array}{l}\text { Unidades } \\
\text { de Uso } \\
\text { Sostenible }\end{array}$} & $\begin{array}{l}\text { Area de Protección } \\
\text { Ambiental }\end{array}$ & $\begin{array}{l}\text { Proteger la diversidad biológica, disciplinar el proceso } \\
\text { de ocupación y asegurar la sostenibilidad de uso de los } \\
\text { recursos naturales. }\end{array}$ \\
\hline & $\begin{array}{c}\text { Área de Interés } \\
\text { Ecológico Relevante }\end{array}$ & $\begin{array}{c}\text { Mantener los ecosistemas naturales de importancia } \\
\text { regional o local. }\end{array}$ \\
\hline & $\begin{array}{l}\text { Floresta Nacional, } \\
\text { Estatal, Municipal }\end{array}$ & $\begin{array}{c}\text { Viabilizar el uso múltiple sostenible de los recursos } \\
\text { forestales y la investigación científica. }\end{array}$ \\
\hline & Reserva de extracción & $\begin{array}{c}\text { Proteger los medios de vida y la cultura de poblaciones } \\
\text { tradicionales y asegurar el uso sostenible de los } \\
\text { recursos naturales. }\end{array}$ \\
\hline & Reserva de Fauna & $\begin{array}{l}\text { Garantizar estudios técnicos y científicos sobre el } \\
\text { manejo económico sostenible de recursos faunísticos. }\end{array}$ \\
\hline & $\begin{array}{l}\text { Reserva de Desarrollo } \\
\text { Sostenible }\end{array}$ & $\begin{array}{c}\text { Preservar la naturaleza y asegurar las condiciones y } \\
\text { medios para la reproducción y la mejora de la calidad de } \\
\text { vida y explotación de los recursos naturales de las } \\
\text { poblaciones tradicionales. }\end{array}$ \\
\hline & $\begin{array}{l}\text { Reserva Particular del } \\
\text { Patrimonio Natural }\end{array}$ & Conservar la diversidad biológica. \\
\hline $\begin{array}{l}\text { Categoría } \\
\text { especial }\end{array}$ & Reserva de la Biosfera & $\begin{array}{l}\text { Integrar distintas áreas de protegidas y otras áreas y } \\
\text { contribuir para la protección ambiental. }\end{array}$ \\
\hline
\end{tabular}

Fuente: SNUC (Ley 9985, de 18 de julio de 2000).

Al comparar el modelo brasileño a experiencias internacionales, Burns y Moreira ${ }^{61}$ identifican algunas similitudes con los modelos alemán y austriaco, aunque el modelo brasileño sea más avanzado, e inspiración de todos los tres en el modelo estadounidense, principalmente en cuanto a los parques nacionales ${ }^{62}$. Sobre otras experiencias relacionadas con áreas protegidas en otros países latinoamericanos,

61 Roberto C. Burns; Jasmine Cardozo Moreira. "Visitor Management in Brazil's Protected Areas: Benchmarking for Best Practices in Resource Management". The George Wright Forum, núm. 2, 2013.

62 Se considera como un marco pionero mundial para las áreas protegidas la creación del Parque Nacional de Yellowstone, en el oeste de los Estados Unidos. 
Andrade Pérez ${ }^{63}$ señala la aplicación del enfoque ecosistémico ${ }^{64}$ a partir de la conexión entre distintas categorías de unidades de conservación, por ejemplo, con las reservas de la Biosfera.

Específicamente sobre el modelo brasileño de áreas protegidas, Garcia (et al) ${ }^{65}$ apuntan que la creación de las unidades de conservación es la más importante acción gubernamental para la protección de la biodiversidad en el país. En ese sentido, según Fonseca (et al) ${ }^{66}$, el SNUC es el principal instrumento legal que permite la fiscalización, gestión y monitoreo de esas áreas protegidas. Además de este avance normativo, dos décadas después de su aprobación, este sistema ha contribuido también con la ampliación en número y en tamaño de áreas protegidas en Brasilib, llevando a números expresivos en los distintos grupos y categorías de unidades de conservación en todas las esferas político-administrativas (cuadro 2).

EI SNUC se ha consolidado como un importante instrumento de la política ambiental brasileña, sea por ordenar distintas categorías de áreas protegidas, sea por la expresividad de las unidades de conservación en número y tamaño. En el año que SNUC cumple dos décadas, el Registro Nacional de Unidades de Conservación apunta $^{68}$ un total de 2.446 unidades, distribuidas en un área ${ }^{69}$ de $2.552 .197 \mathrm{~km}^{2}$. De este total, $1.582 .510 \mathrm{~km}^{2}$ están en el área continental, abarcando aproximadamente

\footnotetext{
63 Ágela Andrade Pérez. Aplicación del enfoque ecosistémico en Latinoamérica. CEM/IUCN. Bogotá, 2007.

${ }^{64}$ Ese enfoque considera la protección ambiental a partir de una visión integrada entre sociedad y ambiente, considerando el conocimiento y la cultura de grupos tradicionales; involucra aún acciones de arriba hasta abajo y de abajo hasta arriba.

65 Lilian Miranda Garcia (et al). "Conceitos Geográficos na gestão das Unidades de Conservação brasileiras". GEOgraphia, núm. 42, 2018.

${ }^{66}$ Anderson José da Silva Fonseca (et al). Reflexões sobre a criação das unidades de conservação no Brasil e o Sistema Nacional de Unidades de Conservação. Revista de Geografia (Recife), núm. 36, 2019, p. 106.

67 Garcia (et al), "Conceitos Geográficos..." cit. Medeiros, Rodrigo (et al). "A proteção da natureza no Brasil: evolução e conflitos de um modelo em construção". RDE - Revista Brasileira de Desenvolvimento Econômico, núm. 9, 2004.

${ }^{68}$ Ministério do Meio Ambiente, "Cadastro..." cit .

${ }^{69}$ Cuando son restadas las superposiciones entre los grupos de Uso Sostenible y de Protección Integral, el valor es de 2.506.199 $\mathrm{km}^{2}$.
} 
$18,66 \%$ del territorio brasileño ${ }^{70}$ y $962.406 \mathrm{~km}^{2}$ son constituidos por unidades de conservación marinas, abarcando $26,46 \%$ del área marina de Brasil ${ }^{71}$. Del total de unidades, 777 son de protección integral, sumando 663.474 km², y 1669 son unidades de uso sostenible, abarcando $1.888 .723 \mathrm{~km}^{2}$.

Cuadro 2: Unidades de conservación de la naturaleza en el SNUC

\begin{tabular}{ccc}
\hline GRUPO/CATEGORIA & Núm. & Ärea $\left(\mathbf{K m}^{\mathbf{2}}\right)$ \\
\hline PROTECCIÓN INTEGRAL & 777 & $\mathbf{6 6 3 . 4 7 4}$ \\
\hline Estación Ecológica & 97 & 119.781 \\
\hline Monumento Natural & 62 & 116.487 \\
\hline Parque Nacional / Estatal / Municipal & 475 & 364.320 \\
\hline Refugio de Vida Silvestre & 77 & 6.637 \\
\hline Reserva Biológica & 66 & 56.249 \\
\hline USO SOSTENIBLE & 1669 & $\mathbf{1 . 8 8 8 . 7 2 3}$ \\
\hline Floresta Nacional / Estatal / Municipal & 108 & 314.009 \\
\hline Reserva de extracción & 95 & 156.217 \\
\hline Reserva de Desarrollo Sostenible & 39 & 112.447 \\
\hline Reserva de Fauna & 0 & 0 \\
\hline Area de Protección Ambiental & 375 & 1.298 .968 \\
\hline Area de Relevante Interés Ecológico & 59 & 1.164 \\
\hline Reserva Particular del Patrimonio Natural & 993 & 5.917 \\
\hline TOTAL & $\mathbf{2 4 4 6}$ & $\mathbf{2 . 5 5 2 . 1 9 7}$ \\
\hline Área sin sobreposición & & 2.506 .199 \\
\hline
\end{tabular}

Fuente: Registro Nacional de Unidades de Conservación/Ministerio del Medio Ambiente de Brasil (MMA, 2018). Actualizada el 28/01/2020.

Además de mostrar que las unidades de conservación se han establecido como una estrategia preponderante para la protección de la naturaleza en Brasil, dada su expresividad en el territorio (cuadro 2; mapa 1), estos dados también apuntan a la existencia de una flexibilidad más grande de usos, teniendo en cuenta que el grupo de uso sostenible es más significativo.

\footnotetext{
${ }^{70}$ Valor porcentual aproximado, considerando la extensión del territorio brasileño como de $8.514 .876 \mathrm{~km}^{2}$ (IBGE, 2002) y sin considerar superposiciones relativas a las áreas de las unidades de conservación.

${ }^{71}$ Se considera como área marina de Brasil el mar territorial y la Zona Económica Exclusiva, totalizando aproximadamente $3.642 .439 \mathrm{~km}^{2}$ (MMA, 2018).
} 
Mapa 1: Unidades de Conservación de la Naturaleza en el territorio brasileño

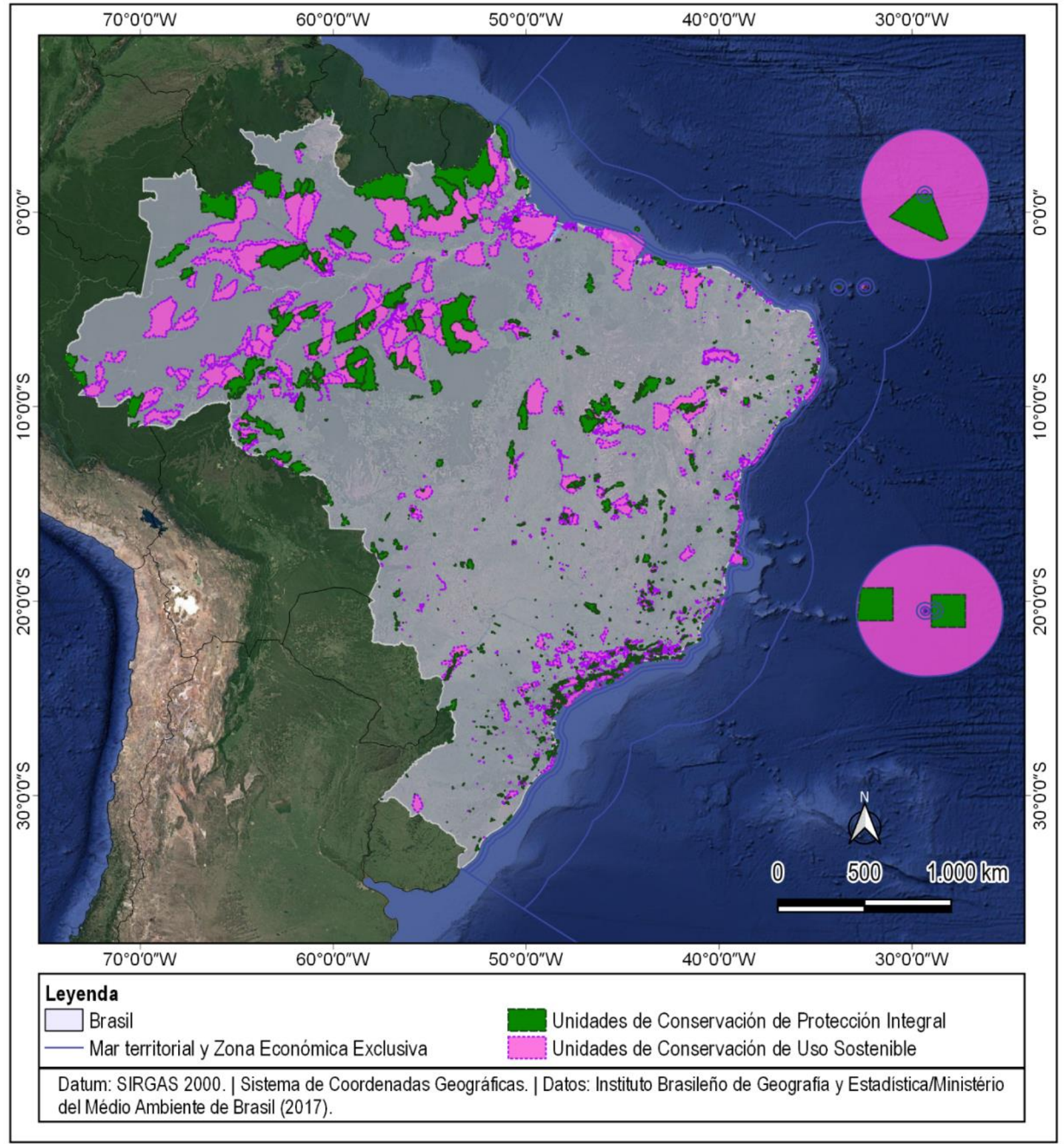

Elaboración propia. Datos: MMA; IBGE.

Sobre la distribución de las unidades de conservación en el territorio brasileño (mapa 1), se nota, además de su expresividad, una concentración muy distinta regionalmente, lo que se relaciona a las características de la política ambiental brasileña y los patrones de ocupación del territorio. Se nota una concentración más 
grande en las porciones norte y noroeste, coincidiendo con el bioma amazónico, que es central en la política ambiental brasileña. Al su rededor, hacia el interior del territorio, hay una zona arqueada donde se nota escasez de áreas protegidas, lo que coincide con la frontera agrícola. Esa frontera agrícola se trata de un prolongamiento del principal núcleo productor en la llamada región Centro-Oeste, donde se verifica fuerte presencia de la agricultura moderna basada en latifundios productores de commodities agrícolas (como la soya) que avanzan sobre el bioma Cerrado, en el cual también se verifica relativamente una presencia más enrarecida de unidades de conservación. Desde la porción central hacia la porción noreste, en la porción semiárida de Brasil, hay otra extensión más significativa de áreas protegidas. A lo largo de la costa, hay distintas áreas en concentración variada, destacándose una concentración en la porción sureste, donde se encuentra la región económica más dinámica del país y la más grande concentración poblacional. En esa área, las unidades de conservación se encuentran mayormente en las zonas de remanentes de la floresta atlántica ${ }^{72}$, funcionando como una estrategia de contención del avance de la ocupación humana sobre la cobertura vegetal.

A pesar de la expresividad de las unidades de conservación en el territorio brasileño, la institución de esas áreas por sí sola no representa la garantía de la protección ambiental. Es necesario problematizar su gestión, lo que requiere un fortalecimiento del aparato institucional relacionado con la protección del medio ambiente en el país, además de una participación efectiva de los diferentes sectores de la sociedad, en vista del carácter transversal de la política ambiental.

En gran medida, las áreas protegidas constituyen barreras a la deforestación, pero también sufren presiones por el avance de esta y otras actividades ilegales, como la quema y la minería ilegal. En fines de la década de 2020, el escenario es muy preocupante para las unidades de conservación y para la política ambiental en su conjunto, especialmente en el bioma amazónico.

\footnotetext{
72 La primera área protegida de Brasil fue justo en la región Sureste, el Parque Nacional de Itatiaia (1938).
} 
Acerca de la deforestación en las unidades de conservación en la Amazonía Legal $^{73}$, considerando datos entre agosto de 2008 y junio de 2019 (gráfico 1), se verifica, después de un periodo inicial de disminución, una tendencia de incremento más expresivo. Si esos problemas ya se verificaban en contextos anteriores, se puede notar, a partir de datos publicados por agencias oficiales, como INPE, que se han acentuado aún más luego del ascenso del gobierno Bolsonaro (2019) ${ }^{74}$, que asigna posiciones de liderazgo a actores vinculados a intereses económicos ${ }^{75}$, además de promover reducciones presupuestarias a organismos oficiales y organizaciones no gubernamentales vinculadas a acciones de protección ambiental.

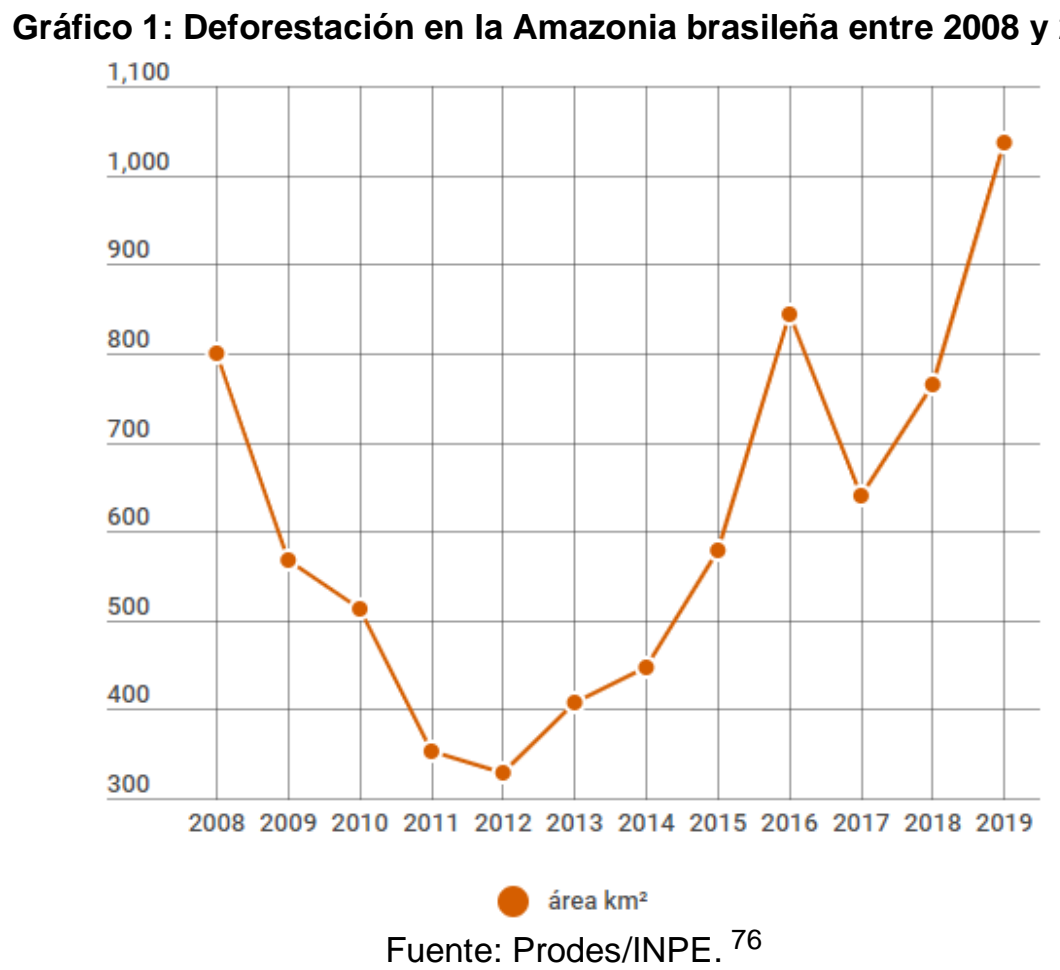

73 La Amazonía Legal Brasileña es una sección regional que abarca los estados brasileños con incidencia, total o parcialmente, del bioma amazónico. Comprende todos los municipios de Rondônia (52), Acre (22), Amazonas (62), Roraima (15), Pará (144), Amapá (16), Tocantins (139), Mato Grosso (141) y 181 municipios del estado de Maranhão ubicados al oeste de Meridiano 44ㅇ $\mathrm{O}$ (Ley Complementaria No. 124, del 3 de enero de 2007). Su superficie aproximada es $5.015 .067 .749 \mathrm{~km}^{2}$, cerca de 58,9\% del territorio brasileño (IBGE; INPE).

${ }^{74}$ Cristiane Prizibisczki. "Desmatamento em Unidades de Conservação atinge maior índice dos últimos 10 anos".

75 Philip Martin Fearnside. "Retrocessos sob o Presidente Bolsonaro: Um desafio à sustentabilidade na Amazônia". Sustentabilidade International Science Journal, núm, 1, 2019, p. 38-52.

${ }^{76}$ Prizibisczki, cit. 
Mapa 2: Unidades de Conservación y deforestación en la Amazonia Legal brasileña (2008-2020)

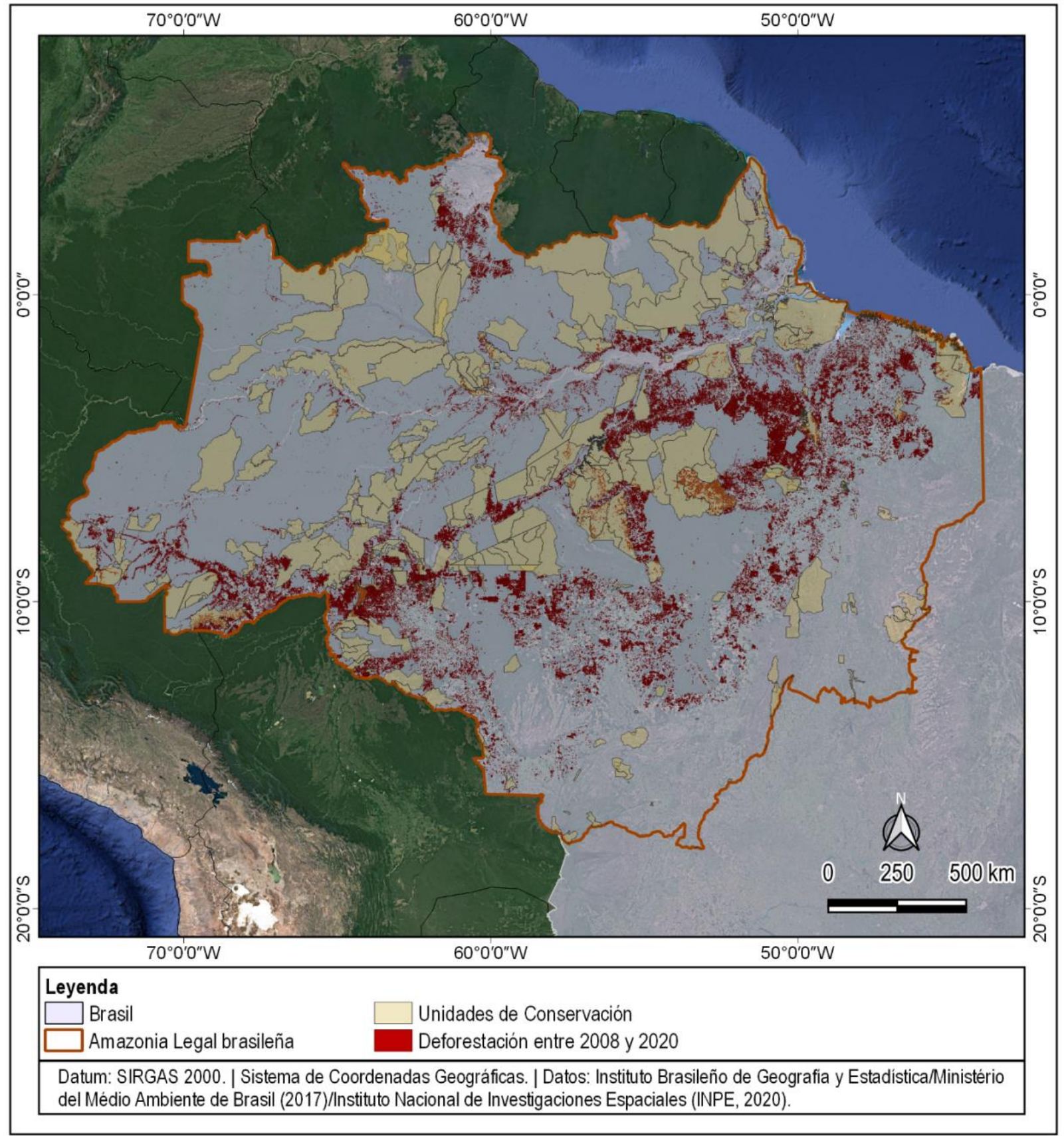

Elaboración propia. Datos de: MMA; IBGE, INPE.

Cuando se analiza el marco legal del SNUC, se puede inferir que su objetivo básicamente es la protección ambiental ${ }^{77}$. Esta noción se refiere justamente a un

77 Ley 9985,18 de julio de 2000 , art. 4ㅇ․ 
conjunto de prácticas para resguardar el patrimonio natural/ambiental, a partir de un régimen especial de uso de determinadas porciones territoriales, las áreas protegidas. La protección ambiental, como una noción más amplia ${ }^{78}$, se desdobla en dos otras nociones distintas y relacionadas ${ }^{79}$, la conservación, que prevé una flexibilidad más grande de usos, y la preservación, que prevé restricciones más grandes de uso ${ }^{80}$.

En gran medida, la conservación y la preservación ambiental aparecen en el texto del SNUC, respectivamente, en los dos grupos de unidades de conservación previstos: uso sostenible y protección integral ${ }^{81}$. Esto permite aseverar que la protección ambiental es, de hecho, la finalidad de ese instrumento de la política ambiental brasileña, que prevé categorías distintas de áreas protegidas de acuerdo con las estrategias de conservación y preservación ambiental.

Al contemplar estas nociones, surgen algunas inquietudes a partir del concepto de territorio usado. Es posible afirmar que protección, conservación y preservación ambiental se relacionan a usos del territorio y a normas territoriales, pero ¿cómo pensar en esas nociones a partir del concepto de territorio usado? Un conjunto más grande de indagaciones parece pertinente: a) ¿Serían esas nociones categorías específicas de usos del territorio? b) ¿Serían expresiones directas de normas territoriales? y c) ¿Sería posible analizar las "unidades de conservación" a partir del concepto de territorio usado?

La protección ambiental, tanto por la estrategia de conservación como de preservación, no es una acción en sí misma, sino que envuelve distintas acciones y normas que denotan determinada relación con los objetos geográficos naturales y artificiales. Como materialización de estas estrategias se presentan las áreas protegidas, que constituyen porciones del territorio dirigidas hacia la regulación del uso de determinados objetos naturales y artificiales, a partir de un régimen especial de control de las acciones, utilizando un aparato normativo para tal.

\footnotetext{
${ }^{78}$ Barbosa, "Aspectos que estruturam o sistema..." cit., p. 42.

${ }^{79}$ Omaira Coromoto García de Berrios (el al). "Conservación y preservación ambiental: lineas de acción educativa para la des-afectación ambiental”. Revista Academia, núm. Especial, 2014.

${ }^{80}$ Medeiros (et al) cit, p. 87.

${ }^{81}$ Ley 9985,18 de julio de 2000 , art. $7^{\circ}$ y $8^{\circ}$.
} 
Sobre esas inquietudes, teniendo en cuenta el análisis realizado en las secciones anteriores y apostando a una concepción integral del ambiente ${ }^{82}$, que incluya concomitantemente y de modo inseparable las acciones sociales y la dinámica natural, es posible hacer las siguientes inferencias.

a. La protección ambiental no es en sí misma una acción, sino que congrega distintas acciones con una finalidad política. Por lo tanto, podría ser reconocida como un conjunto de distintos usos del territorio y, a rigor, como un uso político del territorio. La protección ambiental tiene implicaciones directamente geográficas, es decir, se materializa en el territorio, denota determinada relación de la sociedad con la naturaleza, envolviendo objetos geográficos naturales y artificiales. Sobre la preservación ambiental, esta noción podría ser entendida como una expresión de restricciones de uso, o, paradójicamente, un "no uso", para resguardar el patrimonio ambiental, pero esto debe ser encarado más como principio ${ }^{83}$. La noción de conservación ambiental se demuestra más flexible, por implicar una compatibilización de distintos usos del territorio.

b. La protección ambiental denota también un conjunto de restricciones y una orientación de uso, pues trae limitaciones a determinadas acciones, es decir, regula usos del territorio; los restringe en mayor grado (preservación) o menor grado (conservación); constituye aún, como se defiende en este texto, una regulación que se realiza por un gradiente de usos del territorio.

c. En este sentido, a partir del concepto de territorio usado, las áreas protegidas pueden ser comprendidas como compartimentos territoriales dinámicos, pues son efectivamente usados, o sea, son construcciones normativas (y así sociales y políticas), constituyen materialidades derivadas y animadas por la vida social.

\footnotetext{
82 Santos, "A questão do meio ambiente..." cit.

${ }^{83}$ Las tipologías de unidades de conservación que se orientan por la estrategia de protección ambiental prevén otros usos, como la investigación científica, por ejemplo.
} 
Con esas afirmaciones, es posible esbozar un entendimiento para esas nociones, que constituyen normas territoriales y usos del territorio:

- la protección ambiental constituye un conjunto amplio de usos del territorio y un uso político que se realiza de dos maneras, por la conservación ambiental y por la preservación ambiental;

- la conservación ambiental constituye un uso que incluye una flexibilidad más grande de acciones para la reproducción de los grupos sociales;

- y la preservación ambiental constituye un uso restricto, que denota, en última instancia un "no uso" intencional, dirigido a compartimentos del territorio con características ecológicas excepcionales que necesiten de protección permanentemente integral.

La protección ambiental (que se desdobla en conservación y preservación) es así una regulación del territorio que presupone una serie de acciones a partir de una relación harmónica de los grupos sociales con su medio (el ambiente); es decir, como los agentes animan la materialidad y, así, usan el territorio. Por eso se puede afirmar nuevamente que constituye distintos usos del territorio y normas territoriales.

Es posible identificar una de estas nociones en la propuesta de territorio usado de Santos, cuando el autor, en una reflexión sobre lo que denomina período pretecnico, ejemplifica actividades como barbecho, rotación de tierras y la agricultura itinerante, resaltando que "son al mismo tiempo reglas sociales y reglas territoriales que tienden a conciliar el uso y la 'conservación' de la naturaleza para ser otra vez utilizada." ${ }^{44}$. De este modo, la conservación guardaría usos y estaría vinculada a dicho proyecto de utilización futura, con determinadas reglas, a partir de objetos técnicos que no agredan a la naturaleza. La conservación ambiental constituye entonces y al mismo tiempo un uso del territorio y norma territorial. Se afirma lo mismo para la preservación ambiental, aunque tenga un carácter más restrictivo, y, pues, para la protección ambiental, como una noción más amplia.

En rigor, la protección ambiental se ejecutaría con la finalidad de explotar las potencialidades del territorio sin degradar el ambiente, es decir, de modo que los respectivos agentes usen el territorio y la naturaleza conservándolos y/o preservándolos

${ }^{84}$ Santos, "A questão do meio ambiente..." cit., p. 144 [traducción propia]. 
simultáneamente, lo que envuelve la cohesión entre distintos usos del territorio. Pero eso no quiere decir que estas nociones sean neutrales, sino contrario. Como incluyen distintos usos del territorio y de la naturaleza, protección, conservación y preservación ambiental involucran necesariamente una vasta gama de agentes, que poseen intereses distintos y conflictivos.

Las polémicas sobre la institucionalidad relativa a las áreas protegidas con el cambio de gobierno en Brasil en el 2019 ilustran esos embates sobre la protección ambiental y otros usos del territorio. En una señalización a los sectores productivos primarios, el gobierno Bolsonaro apuesta a la restricción de creación de nuevas áreas protegidas $^{85}$, sugiriendo, aún, la posibilidad de revisión de áreas ya delimitadas ${ }^{86}$. Esa postura del gobierno ha motivado reacciones internacionales incluso en los sectores productivo y financiero ${ }^{87}$, lo que ilustra que la cuestión ambiental es transversal. Es posible y necesario conciliar la producción con la protección ambiental, con el reconocimiento del valor de los objetos naturales en sí mismos para garantizar el equilibrio de los ecosistemas y con estrategias que concilien usos en consonancia con la protección ambiental.

En la perspectiva de autores que defienden que la geografía puede contribuir para el análisis del derecho ambiental y para las políticas con esa temática ${ }^{88}$, se defiende en este texto que la noción de protección ambiental y sus desdoblamientos en conservación y preservación constituyen usos del territorio y, por esa característica, se reitera que componen el conjunto de agentes que animan el territorio o, mejor dicho, todos los agentes, con demandas de uso distintas, como destaca "independientemente de su fuerza diferente, a pesar de su fuerza desigual." ${ }^{89}$. En este sentido:

Una perspectiva de territorio usado conduce a la idea de espacio banal, el espacio de todos, todo el espacio. Se trata del espacio de todos los hombres, no importan sus

\footnotetext{
85 Se destaca la promesa del presidente de "no demarcar ni un centimetro de tierras indígenas". Felipe Milanez. "Cuerpo y alma del fascismo contemporáneo en Brasil", Ecología Política, n. 59, p. 22.

${ }^{86}$ Ricardo Bragança. Ricardo Salles quer rever todas as Unidades de Conservação federais do país e mudar SNUC, O eco, 2019.

87 Beatriz Jucá. "Un grupo de fondos de inversión eleva la presión sobre la política ambiental de Bolsonaro". El País, 2020.

${ }^{88}$ Como Garcia (et al) "Conceitos Geográficos..." cit.

89 Silveira. "Globalización y territorio usado..." cit., p. 3.
} 
diferencias; el espacio de todas las instituciones, no importa su fuerza; el espacio de todas las empresas, no importa su poder. Ese es el espacio de todas las dimensiones del acontecer, de todas las determinaciones de la totalidad social. ${ }^{90}$

Esta reflexión sobre el territorio usado como espacio banal permite visualizar el conjunto de agentes, no únicamente los hegemónicos, sin olvidar la desigualdad de fuerza entre ellos. Como destaca Cataia, "el territorio usado, porque incluye a todos, permite considerar no solamente formas de dominación, sino también de resistencia91" 92. Se esboza entonces el potencial político de la categoría territorio usado"93, "como un instrumento analítico (y al mismo tiempo político) valioso"94.

En este sentido, se demuestra el potencial político de pensar en la protección, la conservación y la preservación ambiental como usos del territorio y de la naturaleza. Por esta calidad, invitan a pensar el conjunto de agentes envueltos, los hegemónicos y no hegemónicos, reconociendo sus fuerzas desiguales. La visualización de los enfrentamientos entre eses agentes puede ser realizada a partir de algunos cuestionamientos básicos acerca del concepto de territorio usado: pensar cómo, dónde, por qué y para qué el territorio es usado ${ }^{95}$. En este sentido el concepto invita a ver los agentes, sus intencionalidades y la propia naturaleza de las relaciones entre ellos.

El referido potencial político de comprender protección, conservación y preservación ambiental como usos del territorio se justifica porque estas nociones, en tal sentido, requieren una visión integradora de los agentes relacionados directa 0 indirectamente con las áreas protegidas - aquellos en el aparato del Estado, las corporaciones, los movimientos sociales, las organizaciones no gubernamentales, las

\footnotetext{
90 Milton Santos (et al). "O papel ativo da geografia: um manifesto". Biblio $3 W$ - Revista Bibliográfica de Geografía y Ciencias Sociales, núm. 270, 2001, párr. 8 [traducción propia].

${ }^{91}$ La historia de las reservas de extracción es emblemática de esa resistência por el uso del territorio. Estas áreas progetidas fueron creadas a principios de la década de 1990 a partir de la lucha de los recolectores de caucho contra los proyectos de colonización promovidos en la Amazonía desarrollados en la década de 1970, durante la dictadura militar en Brasil. Estos proyectos se centraron en la deforestación de la Amazónia para la expansión de la agricultura; en contraste, los recolectores de caucho lucharon por su permanencia en la tierra, apuntando a una economía que no es perjudicial para el ambiente, teniendo en cuenta sus prácticas extractivas y la producción familiar de alimentos.

${ }^{92}$ Cataia, "Território político..." cit., p. 124.

${ }^{93}$ Gomes (et al), "O potencial político..." cit.

94 Mirlei Fachini Vicente Pereira. "Território e política: práxis invertidas e desafios da existência". Sociedade \& Natureza, 23 (2011), pp. 95-104.

${ }^{95}$ Santos; Silveira, "O Brasil..." cit.
} 
comunidades tradicionales, las instituciones de investigación, las empresas, los pequeños y grandes productores, además de otros sectores de la sociedad civil. En este sentido, pensando a partir del uso del territorio y de la naturaleza, esos distintos agentes podrían tener voz en el debate, y no solamente los hegemónicos, presentándose como actores en el proceso de políticas públicas relativo a la creación, la implementación y la gestión de las áreas protegidas.

Además de la visibilidad y de la posible voz a esos agentes, la comprensión de la protección, la conservación y la preservación ambiental como usos del territorio también torna visible el embate de fuerzas entre ellos en la materialización de estos usos, ya que los intereses implicados son tan diversos cuanto son los agentes. Pensados en términos de protección ambiental en el ámbito de la política ambiental brasileña, estos distintos usos del territorio se materializan en las áreas protegidas, específicamente en las unidades de conservación.

Como se evidencia en la concepción de tal instrumento de política pública, se trata de la presentación de la protección, la conservación y la preservación ambiental como normas territoriales, pues constituyen, en el marco del SNUC, estrategias de regulación de compartimentos del territorio usado, las áreas protegidas por él denominadas "unidades de conservación".

\section{CONSIDERACIONES FINALES}

El modelo brasileño de áreas protegidas tiene al SNUC como uno de sus principales elementos, que busca promover la protección ambiental en escala nacional a partir de articulación conjunta en distintas esferas político-administrativas, con el establecimiento de unidades de conservación nacionales, estatales/distritales y municipales en Brasil.

A partir de las áreas protegidas, el SNUC se materializa en el territorio brasileño y tiene implicaciones en la dinámica de sus usos. Se trata de la difusión de la protección ambiental como norma y como uso en el territorio, por medio de la inducción o represión de determinados usos en estos compartimentos territoriales.

Las unidades de conservación y otras categorías de áreas protegidas se orientan hacia la regulación del uso de determinados objetos naturales y artificiales, a partir de 
un régimen especial de control de acciones, utilizando un aparato normativo con el objetivo de promover la protección ambiental, que puede ser entendida como norma y uso del territorio.

Como norma territorial, la protección ambiental presupone una serie de acciones a partir de una relación harmónica de los grupos sociales con su medio. También puede ser entendida como un conjunto amplio de usos del territorio y un uso político que se realiza por la conservación ambiental, que implica una mayor flexibilidad de acciones para la reproducción de los grupos sociales, y la preservación ambiental, lo que constituye un uso más restricto, centrado en compartimentos del territorio con características excepcionales que carecen de protección integral.

Sobre el contexto de las áreas protegidas brasileñas a finales de la década de 2020, se nota que, a pesar de su expresividad en el territorio, la gestión de esas áreas está bastante amenazada por el avance de la deforestación, las quemas y la minería ilegal, actividades intensificadas con el desmantelamiento de las políticas ambientales y las restricciones a la actuación de los órganos de supervisión ${ }^{96}$.

Aunque la legislación brasileña sea bastante avanzada como norma, hay que garantizar su efectiva implementación para lograr la protección ambiental en el uso del territorio, lo que necesariamente implica relaciones de poder. En este sentido, es necesario identificar los actores sociales y políticos involucrados y conocer su actuación a favor 0 en contra de la agenda ambiental.

Es relevante pensar entonces en la protección ambiental a partir de la dinámica territorial, reflexión que puede ser realizada a partir de su entendimiento como norma y como uso del territorio. Este raciocinio, además de un potencial político, pues permite denunciar los abusos y dar voz a los actores no hegemónicos, puede contribuir para el mejoramiento y la evaluación del sistema brasileño de áreas protegidas en consonancia con las dinámicas territoriales, visualizando los distintos actores sociales implicados, resultado del posible diálogo entre la teoría geográfica y la planificación en su dimensión ambiental-territorial.

\footnotetext{
96 Camilla Veras Mota. Desmonte sob Bolsonaro pode levar desmatamento da Amazônia a ponto irreversível, diz físico que estuda floresta há 35 anos, BBC News Brasil. 2019.
} 


\section{BIBLIOGRAFÍA}

Andrade Pérez, A. (Coord.). Aplicación del enfoque ecosistémico en Latinoamérica. CEM/IUCN. Bogotá, 2007.

Antas Jr, R. M. Território e regulação: espaço geográfico como fonte material e nãoformal do direito. Humanitas/FAPESP. São Paulo, 2005.

Barbosa, H. C. "Aspectos que estruturam o sistema nacional de unidades de conservação da natureza". Revista Jurídica da UniFil, núm. 5, 2018, p. 38-54. Recuperado de <http://periodicos.unifil.br/index.php/rev-juridica/article/view/613/564> [Última consulta, 13 de mayo de 2020].

Bragança, R. Ricardo Salles quer rever todas as Unidades de Conservação federais do país e mudar SNUC. $O$ eco, 2019. Recuperado de $<$ https://www.oeco.org.br/noticias/ricardo-salles-quer-rever-todas-as-unidades-deconservacao-federais-do-pais-e-mudar-snuc/>. [Última consulta, 17 de septimbre de 2020].

Burns, R. C.; Moreira, J. C. "Visitor Management in Brazil's Protected Areas: Benchmarking for Best Practices in Resource Management". The George Wright Forum, núm. 2, 2013, p. 163-170. Recuperado de <http://www.georgewright.org/302burns.pdf> [Última consulta, 13 de mayo de 2020].

Cataia, M. A. "Território político: fundamento e fundação do Estado". Sociedade \& Natureza, núm. 1, 2011, p. 115-125. Recuperado de <https://doi.org/10.1590/S198245132011000100010>.

Fearnside, P. M. 2019. "Retrocessos sob o Presidente Bolsonaro: Um desafio à sustentabilidade na Amazônia". Sustentabilidade International Science Journal, núm, 1, p. 38-52. Recuperado de: <http://cca.ufam.edu.br/pdf/Revista Sustentabilidade 28-062019\%20(1\%C2\%AA\%20Edicao).pdf>. [Última consulta, 16 de septimbre de 2020]

Ferreira Filho, M. G. Curso de direito constitucional. São Paulo: Saraiva, 2015.

Fonseca, A. A. J. S. (et al). Reflexões sobre a criação das unidades de conservação no Brasil e o Sistema Nacional de Unidades de Conservação. Revista de Geografia (Recife), núm, 36, 2019, p. 97-111. Recuperado de <https://periodicos.ufpe.br/revistas/revistageografia/article/download/239824/34074>. [Última consulta, 13 de mayo de 2020].

Garcia, L. M. (et al). "Conceitos Geográficos na gestão das Unidades de Conservação brasileiras". GEOgraphia, núm. 42, 2018, p. 53-62, <https://doi.org/10.22409/GEOgraphia2018.v20i42.a13832>.

Garcia de Berrios, O. (et al). "Conservación y preservación ambiental: lineas de acción educativa para la des-afectación ambiental". Revista Academia, núm. Especial, 2014, p. 
47-57. Recuperado de <http://bdigital.ula.ve/storage/pdf/academia/v13ns1/art05.pdf> [Última consulta, 13 de mayo de 2020].

Gomes, M. S (et al). "O potencial político da categoria 'território usado". En: Steinberger, M. (Coord.). Território, Estado e políticas públicas espaciais. Ler Editora. Brasilia, 2013, p. 65-87.

Jucá, B. Un grupo de fondos de inversión eleva la presión sobre la política ambiental de Bolsonaro. El País, 2020. Recuperado de https://elpais.com/internacional/2019/09/18/actualidad/1568838133 361572.html. [Ültima consulta, 18 de septiembre de 2020].

Leuzinger, M. D. (et al). Direito Ambiental. Rio de Janeiro: Elsevier, 2008.

Medeiros, R. Evolução das tipologias e categorias de áreas protegidas no Brasil. Ambiente \& Sociedade, núm 1, 2006, p. 41-64, <https://doi.org/10.1590/S1414753X2006000100003>.

Medeiros, R. (et al). "A proteção da natureza no Brasil: evolução e conflitos de um modelo em construção". RDE - Revista Brasileira de Desenvolvimento Econômico, núm. $\quad 9,2004, \quad$ p. 83-93. Recuperado de $<$ https://revistas.unifacs.br/index.php/rde/article/view/115>. [Última consulta, 13 de mayo de 2020].

Milanez, F. "Cuerpo y alma del fascismo contemporáneo en Brasil", Ecología Política, n. 59, p. 17-23. $\quad$ Recuperado de $<$ https://dialnet.unirioja.es/servlet/articulo?codigo=7528855>. [Última consulta, 15 de septiembre de 2020].

Mota, C. V. Desmonte sob Bolsonaro pode levar desmatamento da Amazônia a ponto irreversível, diz físico que estuda floresta há 35 anos. BBC News Brasil, 2019. Recuperado de < https://www.bbc.com/portuguese/brasil-48805675 >. [Última consulta, 18 de septiembre de 2020].

Ministério do Meio Ambiente (Brasil). Cadastro Nacional de Unidades de Conservação. Recuperado de <http://www.mma.gov.br/areas-protegidas/cadastro-nacional-de-ucs> [Última consulta, 13 de mayo de 2020].

Pereira, M. F. V. "O antagonismo das normas territoriais no sudoeste da Amazônia: território usado e conflito de interesses em Rondônia e Acre". Geografia, Num. Especial, 2011, pp. 107-117.

Pereira, M. F. V. "Território e política: práxis invertidas e desafios da existência". Sociedade \& Natureza, 23 (2011), pp. 95-104. Recuperado de $<$ https://dx.doi.org/10.1590/S1982-45132011000100008>. 
Pereira P. F.; Scardua, F. P. "Espaços territoriais especialmente protegidos: conceito e implicações jurídicas". Ambiente \& Sociedade, núm, 1, 2008, p. 81-97. Recuperado de $<$ https://doi.org/10.1590/S1414-753X2008000100007>.

Prizibisczki, C. "Desmatamento em Unidades de Conservação atinge maior índice dos últimos 10 anos". $O$ Eco. Recuperado de < https://www.oeco.org.br/reportagens/desmatamento-em-unidades-de-conservacaoatinge-maior-indice-dos-ultimos-10-anos/>.

Ribeiro, A. C. T. "Território usado e humanismo concreto: o mercado socialmente necessário". En: Ribeiro, A. C. T. (et al). Formas em crise: utopias necessárias. Arquimedes Edições. Rio de Janeiro, 2005, p. 194-212.

Santos, M. A natureza do espaço: técnica e tempo, razão e emoção. Editora da Universidade de São Paulo. São Paulo, 2008.

Santos, M. "O retorno do território". Observatorio Social de América Latina. núm. 16, $2005 . \quad$ p. 251-261. Recuperado de $<$ http://bibliotecavirtual.clacso.org.ar/ar/libros/osal/osal16/D16Santos.pdf> [Última consulta, 13 de mayo de 2020].

Santos, M. "A questão do meio ambiente: desafios para a construção de uma perspectiva transdisciplinar". GeoTextos, núm. 1, 2006, p. 139-151, $<$ http://dx.doi.org/10.9771/1984-5537geo.v1i1.3033>.

Santos, M. "O Território e o Saber Local: algumas categorias de análise". Cadernos IPPUR, núm. 2, 1999, p. 15-26.

Santos, M. Por uma geografia nova: da crítica da geografia a uma geografia critica. Hucitec. São Paulo, 1986.

Santos, M. (et al). "O papel ativo da geografia: um manifesto". Biblio $3 W$ - Revista Bibliográfica de Geografía y Ciencias Sociales, num. 270, 2001. Recuperado de $<$ http://www.ub.edu/geocrit/b3w-270.htm> [Última consulta, 13 de mayo de 2020].

Santos, M.; Silveira, M. L. O Brasil: território e sociedade no início do século XXI. Record. Rio de Janeiro, 2008.

Silveira, M. L. "Globalización y territorio usado: imperativos y solidaridades". Cuadernos del CENDES, núm. 69, 2008, p. 1-19. Recuperado de $<$ https://www.redalyc.org/pdf/403/40311392002.pdf> [Última consulta, 13 de mayo de 2020].

Silveira, M. L. "Concretude territorial, regulação e densidade normativa". Experimental, núm. 2, 1997, p. 35-45. 